\title{
Evolution of the spherical cavity radius generated around a subsurface drip emitter
}

\author{
M. Gil, L. Rodríguez-Sinobas, R. Sánchez, and L. Juana \\ Irrigation Hydraulics Research Group, Technical University of Madrid, E. T. S. I. Agrónomos, Ciudad Universitaria s/n, \\ 28040 Madrid, Spain
}

Received: 15 January 2010 - Published in Biogeosciences Discuss.: 18 March 2010

Revised: 21 May 2010 - Accepted: 31 May 2010 - Published: 22 June 2010

\begin{abstract}
The emitter discharge in subsurface drip irrigation can be affected by soil properties. A positive pressure develops at the emitter outlet where a spherical cavity is assumed to form. In steady-state conditions, the pressure in the soil relates to soil hydraulic properties, the emitter discharge, and the cavity radius. This pressure in the soil is very sensitive to the cavity radius. In this paper, the development of the cavity around the emitter outlet was measured for various emitter discharges in laboratory tests carried out in containers with uniform loamy soils. A trend between soil pressure and emitter discharge was established that illustrates the performance of buried emitters in the field. Its application to the prediction of water distribution in subsurface drip irrigation units and its effect on the estimation of irrigation performance are also shown.
\end{abstract}

\section{Introduction}

Subsurface drip irrigation (SDI) is one of the most advanced irrigation methods (Patel and Rajput, 2008). In SDI, emitter discharge can be affected by soil hydraulic properties, which can cause non-uniformity in water application in some types of soils (Lazarovicth et al., 2006; Rodriguez-Sinobas et al., 2009a). It is believed that, for certain soils, a subsurface emitter usually forms a limiting cavity around its outlet into which water can flow freely (Philip, 1992; Ben-Gal et al., 2004). When the emitter discharge is not too high, this saturated region is close to spherical (Philip, 1992). As the porous space at the emitter outlet fills with water, infiltration of applied water is limited by the hydraulic properties of the

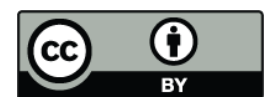

Correspondence to: M. Gil

(maria.gil@upm.es) soil, resulting in the development of positive soil pressure $h_{\mathrm{s}}$ (Shani and Or, 1995; Shani et al., 1996; Gil et al., 2007, 2008).

The relationship between pressure head and emitter discharge follows this potential equation (Karmeli and Keller, 1975):

$q=k \cdot h_{0}^{x}$

where $q$ is the emitter discharge, $h_{0}$ is the operating pressure head, and $k$ and $x$ are the emitter coefficient and exponent, respectively.

Shani et al. (1996) measured the water pressure at the emitter outlet in several soils in the field. If an overpressure $h_{\mathrm{s}}$ develops in the soil, at the discharge point of a buried emitter, the hydraulic gradient between the emitter interior and the soil will decrease and $q$ will become the following (Warrick and Shani, 1996; Gil et al. 2008):

$q=k \cdot\left(h_{0}-h_{\mathrm{s}}\right)^{x}$

Philip (1992) analyzed the conditions of flow movement in a continuously flowing subsurface point source. Shani and Or (1995) used Philip's conclusions to relate, at steady-state conditions, $h_{\mathrm{s}}$ to the soil hydraulic properties and the source discharge, $q$ :

$h_{\mathrm{s}}=\left(\frac{2-\alpha_{\mathrm{G}} \cdot r_{0}}{8 \pi \cdot K_{\mathrm{s}} \cdot r_{0}}\right) \cdot q-\frac{1}{\alpha_{\mathrm{G}}}$

where $r_{0}$ is the radius of the spherical cavity, $K_{\mathrm{S}}$ is the saturated hydraulic conductivity of the soil, and $\alpha_{\mathrm{G}}$ is the parameter for the unsaturated hydraulic conductivity from Gardner's equation (Gardner, 1958).

Note that $h_{\mathrm{s}}$ is very sensitive to $r_{0}$; in most of the previous studies regarding the simulation or calculation of emitter performance, $r_{0}$ has been a constant, independent of emitter

Published by Copernicus Publications on behalf of the European Geosciences Union. 
discharge (Lazarovitch et al., 2005; Shani et al., 1996, Gil et al., 2008); in other cases, $r_{0}$ has been determined from the known values of the other variables in Eq. (3) measured in experimental tests (Shani et al., 1996, Gil et al., 2008). Thus, a linear relationship between the estimated $r_{0}$ and emitter discharge, $q$, has been proposed; however, to date, no studies have reported any in situ observation of the cavity development around the emitter outlet.

Publications dealing with the prediction of waterdistribution uniformity in SDI laterals and units are scarce, wherein most do not consider the soil overpressure at the emitter outlet. This was considered in the studies of Warrick and Shani (1996) and Lazarovitch et al. (2006), who simulated the water distribution in a branched SDI unit and in SDI laterals in different soils with different emitter discharges. They estimated the soil spatial variability, but considered $r_{0}$ to be a constant.

Rodriguez-Sinobas et al. (2009a) developed a computer program for estimating water distribution in SDI laterals and looped units that were buried in uniform soils and in soils with spatial variabilities, while also considering $r_{0}$ to be a constant. Values for $h_{\mathrm{s}}$ and the emitter discharge variation were provided by the manufacturer and included in their calculations. In a subsequent study, their simulations were compared with field evaluations (Rodriguez-Sinobas et al., 2009 b), wherein the results indicate that uniformity was generally higher in laterals and units that were buried in uniform soils than those placed on the surface; however, when spatial variability was considered, SDI was less uniform than surface drip irrigation.

The objectives of this study were to observe the development of a spherical cavity around the emitter outlet and to calculate the relationship between emitter discharge, $q$, and the directly measured $r_{0}$. Subsequent application of this relation to the prediction of water distribution in SDI units was used to illustrate its effectiveness in the estimation of SDI performance.

\section{Materials and methods}

\subsection{Experimental procedure}

A cross-sectional cut dividing a 15-L pot into two halves was made to observe the development of the cavity in the soil around the emitter outlet. An acrylic sheet was attached to one of these halves, creating a closed container.

The pot size could be considered small; however, it didn't affect the results. It would have affected the cavity if the water had reached the walls. In that case, the pressure in the soil would have risen causing an increase in the cavity size.

A 6-mm internal-diameter acrylic pipe was cut lengthwise and attached to the central axis of the sheet (Fig. 1a). The pipe end was $11 \mathrm{~cm}$ below the soil-sample surface.

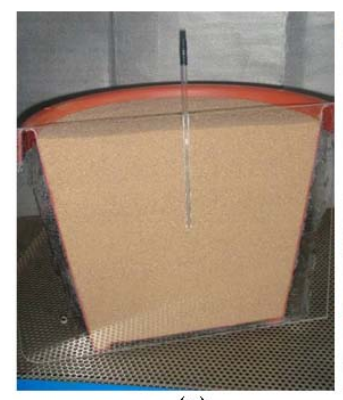

(a)

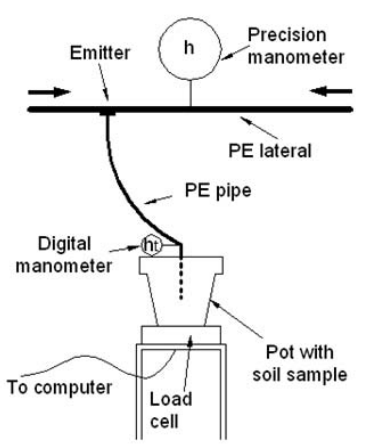

(c)

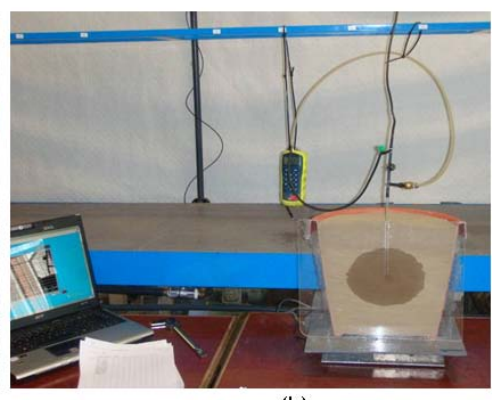

(b)

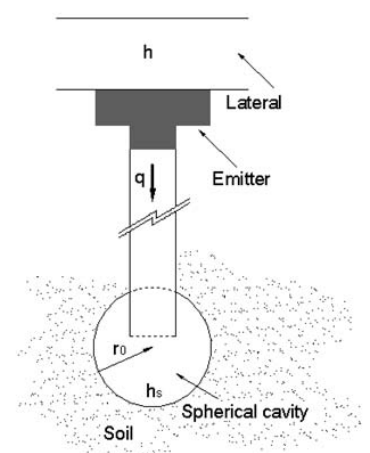

(d)
Fig. 1. Experimental procedure. (a) Cross-section of the pot; (b) Measurement setup; (c) Sketch of the installation; (d) Variables involved in the cavity development.

The acrylic pipe was connected through a 6-mm-diameter polyethylene (PE) pipe to an emitter inserted into a $1.5 \mathrm{~m}$ lateral fed from both ends (Fig. 1b, c, and d). $h_{0}$ was measured at the lateral midpoint by a precision manometer $( \pm 0.25 \% \mathrm{MPa})$ and was kept constant throughout the test. The PE pipe pressure $h_{t}$ was measured using a digital manometer $( \pm 0.01 \mathrm{~m})$. The pressure at the discharge point $h_{\mathrm{s}}$ was determined by adding the difference in elevation (approximately $20 \mathrm{~cm}$ ) between the manometer insertion point and the extreme of the buried tube to the pressure.

Two different models of punched emitters, with nominal discharges of 2 and $4 \mathrm{~L} / \mathrm{h}$, were studied. They were tested at different pressures within a large emitter-discharge interval. Two soils with different textures were selected to observe the effect of soil properties on emitter discharge: a sandy soil and a loamy soil. The soils were screened using a mesh sieve with 1-mm openings.

The Bouyoucos method of densimetry was used to determine the texture of the soil samples in the laboratory (Table 1). The bulk density was set at $1.4 \mathrm{~g} / \mathrm{cm}^{3}$ for both soils. The procedure for filling the pots consisted of adding a constant weight of soil to each pot that was then compacted down to a previously calculated height equivalent to a determined volume.

In each trial, the time evolution of the emitter discharge was measured for the pot. It was weighed on a load cell with 
Table 1. Proportion of sand, silt, and clay in the soils as determined by the Bouyoucos densimetry method.

\begin{tabular}{lcc}
\hline & Sandy soil & Loamy soil \\
\hline Sand (\%) & 91.2 & 50.3 \\
Silt (\%) & 7.5 & 31.9 \\
Clay (\%) & 1.3 & 17.8 \\
\hline
\end{tabular}

a nominal load of $20 \mathrm{~kg}( \pm 0.002 \mathrm{~kg})$. A data-acquisition card was used to record the pot weight onto a computer every three seconds. The application time was set by the time that the pressure required to become stabilized.

The values of the hydraulic soil parameters $\alpha_{\mathrm{G}}$ and $K_{\mathrm{S}}$ were determined using the ROSETTA code. This program calculates water-retention-curve parameters for the van Genuchten-Mualem's model (residual soil water content $\theta_{\mathrm{r}}$, saturated soil water content $\theta_{\mathrm{s}}$, exponent in soil water retention $n$, and coefficient in the soil water retention function $\alpha$ ); and saturated-soil hydraulic conductivity $K_{\mathrm{S}}$ as a function of soil texture class sand, silt, and clay percentages; and soil bulk density (Table 4). Next, the $\alpha_{\mathrm{G}}$ parameter of Gardner's model was estimated by equating the Kirchhoff potential:

$\phi=\int_{-\infty}^{0} K(h) d h$

of this model to the Mualem-van Genuchten hydraulic model, and substituting:

$\alpha_{\mathrm{G}}=\frac{K_{\mathrm{s}}}{\phi}$

Integration of Eq. (4) was performed numerically and the cavity radius was calculated for each case using the equation:

$r_{0}=\frac{2 \cdot q \cdot \alpha_{\mathrm{G}}}{8 \pi \cdot K_{\mathrm{S}} \cdot\left(\alpha_{\mathrm{G}} \cdot h_{\mathrm{s}}+1\right)+\left(\alpha_{\mathrm{G}}^{2} q\right)}$

\subsection{Prediction of water distribution in SDI units considering a variable $r_{0}$}

A MATLAB pine the effect of cavity radius, $r_{0}$, variation on the performance of SDI units. The program calculation process and flowchart are explained in Rodriguez-Sinobas et al. (2009a).

Typically, SDI units are composed of looped networks. Water can move either direction, from the head to the downstream lateral and in reverse, such that the direction of flow is unknown. The simulated unit characteristics of pipe length $(L)$, internal diameter $(D)$, equivalent length $\left(l_{\mathrm{e}}\right)$, separation of emitter and lateral $(s)$, and manufacturer's coefficient of variance $\left(C V_{m}\right)$ are depicted in Table 2 .

The lateral inlet pressure was $20 \mathrm{~m}$. The simulated emitters had an $x$ exponent of 0.5 and $k$ coefficients selected in
Table 2. Simulated SDI unit characteristics.

\begin{tabular}{lll}
\hline & Laterals & Submain \\
\hline$L(\mathrm{~m})$ & 50 & 40 \\
$D(\mathrm{~mm})$ & 14 & 100 \\
$l_{\mathrm{e}}(m)$ & 0.3 & 0.5 \\
$s(\mathrm{~m})$ & 0.5 & 0.75 \\
$C V_{m}$ & 0.05 & - \\
\hline
\end{tabular}

the range from 0.7 to 1.6 , resulting in a range of different discharges that matched those used in other laboratory experiments. A uniform soil was assumed (no spatial variability); the saturated hydraulic conductivity, $K_{\mathrm{s}}$, was $2.8 \times 10^{-5} \mathrm{~m} / \mathrm{s}$ and $\alpha_{\mathrm{G}}$ was 4.5 .

The MATLAB program developed in this study determined the discharges and pressures at the inlet and downstream end of the laterals, the distributions of emitter discharges and emitter pressures, and the irrigation-uniformity index, i.e., the coefficient of variation of the emitter discharge, $C V_{q}$. Simulations were performed for two situations, assuming either a constant or variable $r_{0}$. The latter simulations were calculated for each emitter outlet from the $q-r_{0}$ relationships obtained from the tests, whereas the former simulation was calcuated using a constant $r_{0}$ equal to the average of the values of $r_{0}$ used in the latter simulations.

\section{Results and discussion}

\subsection{Results of the laboratory tests}

In the tests using sandy soil, a semi-ellipsoidal cavity was observed, but it was so small that it was impossible to measure. Furthermore, an increase in cavity size as a function of increasing discharge was not observed. Therefore, the results shown below refer only to tests using loamy soil.

In the loamy soil, the cavities formed (Fig. 2) could be easily measured. Cavity size was observed to increase with time and then stabilize (Video 1). In the video, it can also be seen that the water carried away some soil particles.

At the beginning of irrigation, the cavity was star-shaped, but as the experiment proceeded, the cracks at the points of the star-shaped cavity were filled with suspended soil particles, resulting in a spherical-shaped cavity. For lower discharges, the cavity tended to be spherical in shape, whereas for higher discharges, cracks observed early on in the experiment became filled with material. At higher discharge rates, it took longer to fill the large cracks developed at the beginning of irrigation with soil material.

Cracks were mainly horizontal probably because the pots were filled with horizontal layers. Soils in the field have structure, thus cracks could not necessarily be horizontal. 


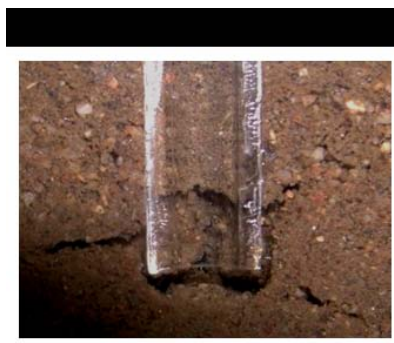

(a)

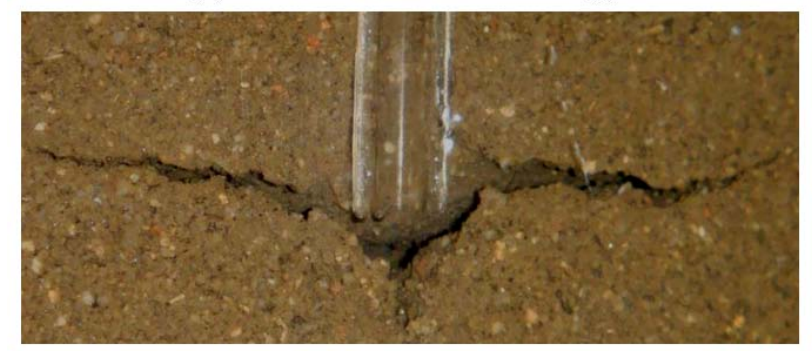

(c)

Fig. 2. Examples of developed cavities. (a) $q=4.21 \mathrm{~L} / \mathrm{h}$; (b) $q=$ $5.13 \mathrm{~L} / \mathrm{h} ;$ (c) $q=7.88 \mathrm{~L} / \mathrm{h}$.

Table 3. Results of the tests.

\begin{tabular}{lccccc}
\hline Emitter & $h(\mathrm{~m})$ & $h_{\mathrm{s}}(\mathrm{m})$ & $q(\mathrm{~L} / \mathrm{h})$ & Area $\left(\mathrm{mm}^{2}\right)$ & $r_{0}$ equiv $(\mathrm{m})$ \\
\hline A & 5 & 0.6 & 3.05 & 20.19 & 0.0025 \\
A & 10 & 0.6 & 4.21 & 57.20 & 0.0043 \\
A & 12 & 0.6 & 4.63 & 69.37 & 0.0047 \\
A & 15 & 0.5 & 5.13 & 95.33 & 0.0055 \\
B & 6 & 0.6 & 6.16 & 142.40 & 0.0060 \\
B & 10 & 0.5 & 7.88 & 191.92 & 0.0068 \\
B & 15 & 0.6 & 9.40 & 202.13 & 0.0070 \\
\hline
\end{tabular}

Table 3 shows the results of the tests for the loamy soil, including the area of the resultant cavities and the radius that the cavities would have had if they were spherical ( $r_{0}$ equiv.); the emitter mean discharge, $q$; and the pressures $h_{0}$ and $h_{\mathrm{s}}$.

As can be observed from Table 3, higher discharge rates resulted in larger measured cavity areas. Therefore, $r_{0}$ equiv. also increased with emitter discharge. This trend is depicted in Fig. 3. For lower discharges, the increase in $r_{0}$ was linear, but tended to stabilize at higher values.

As expected, $h_{\mathrm{s}}$ increased suddenly at the beginning of the tests and then decreased. The decrease was quick at the start of irrigation, becoming more gradual with time until the pressure became stabilized (Fig. 4). This decrease in pressure over time coincided with an increase in cavity radius.

Increasing the emitter discharge did not increase the final value of $h_{\mathrm{s}}$. This pressure remained at $0.5-0.6 \mathrm{~m}$ in all the tests, although the discharge varied from 3.05 to $9.40 \mathrm{~L} / \mathrm{h}$. These results agree with those of the authors' previous studies carried out with the same soil (Gil et al., 2007, 2008); however, these results conflict with observations made by

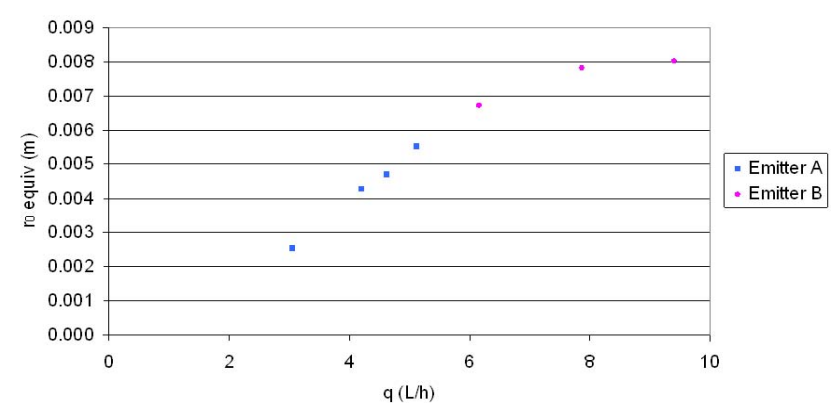

Fig. 3. Spherical-cavity radius, $r_{0}$, versus emitter discharge, $q$.

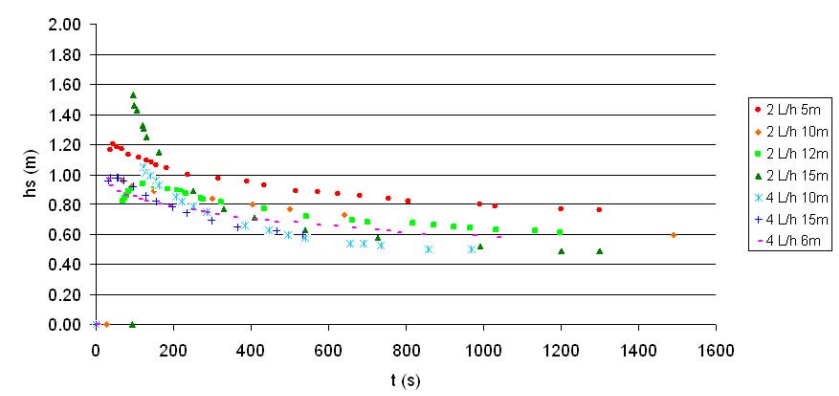

Fig. 4. Evolution of pressure in the soil around the emitter outlet $\left(h_{S}\right)$ as a function of time.

other authors (Shani et al., 1996) using soils from fields, wherein $h_{\mathrm{s}}$ was observed to increase with emitter discharge. This discrepancy could be explained by different soil properties in these experiments, or that soil in a field has a different structure in comparison to soil in pots, making the mechanical behaviors of field soils and pot soils significantly different.

The cavity radius, $r_{0}$, was also calculated from the soil hydraulic parameters, $K_{\mathrm{s}}$ and $\alpha_{\mathrm{G}}$ (Table 4 ); the emitter discharge, $q$; and the soil pressure around the emitter outlet, $h_{\mathrm{s}}$. The calculated values were larger than the measured values (Fig. 5a); however, the same trend that $r_{0}$ increased linearly for small emitter discharges and then stabilized was observed.

If the value of $K_{\mathrm{s}}$ was modified, the measured and estimated values of $r_{0}$ were better matched. $K_{\mathrm{S}}$ was increased because in a previous test with the same soil, the value of $K_{\mathrm{S}}$ was measured with a falling permeameter to be approximately $10^{-5} \mathrm{~m} / \mathrm{s}$. Thus, a value of $2.8 \times 10^{-5} \mathrm{~m} / \mathrm{s}$ could be

Table 4. Soil hydraulic properties for the van Genuchten-Mualem model estimated by ROSETTA code and Gardner's $\alpha$ parameter.

\begin{tabular}{lccccc}
\hline$\theta_{r}\left(\mathrm{~m}^{3} / \mathrm{m}^{3}\right)$ & $\theta_{s}\left(\mathrm{~m}^{3} / \mathrm{m}^{3}\right)$ & $\alpha\left(\mathrm{m}^{-1}\right)$ & $n$ & $K_{\mathrm{S}}(\mathrm{m} / \mathrm{s})$ & $\alpha_{\mathrm{G}}\left(\mathrm{m}^{-1}\right)$ \\
\hline 0.0567 & 0.4130 & 1.3 & 1.5 & $3.2 \times 10^{-6}$ & 4.5 \\
\hline
\end{tabular}


Table 5. Results of simulations in an SDI unit, with an inlet pressure of $20 \mathrm{~m}$, in different soils and for different emitter discharges.

\begin{tabular}{lccccccc}
\hline$K$ & & 0.7 & 0.8 & 1.0 & 1.2 & 1.4 & 1.6 \\
\hline \multirow{4}{*}{ Constant $r_{0}$} & $q$ & 3.02 & 3.41 & 4.23 & 5.01 & 5.66 & 6.54 \\
& $h_{\mathrm{S}}$ & 1.07 & 0.83 & 0.64 & 0.59 & 0.59 & 0.63 \\
& $C V_{q}$ & 0.0070 & 0.0081 & 0.0107 & 0.0136 & 0.0168 & 0.0227 \\
& $r_{0}$ & 0.0018 & 0.0025 & 0.0038 & 0.0048 & 0.0054 & 0.0060 \\
Variable $r_{0}$ & $q$ & 3.02 & 3.41 & 4.23 & 5.01 & 5.66 & 6.54 \\
& $h_{\mathrm{S}}$ & 1.10 & 0.84 & 0.65 & 0.59 & 0.59 & 0.63 \\
& $C V_{q}$ & 0.0090 & 0.0094 & 0.0115 & 0.0144 & 0.0175 & 0.0233 \\
$C V_{q}$ variation $(\%)$ & 0.0018 & 0.0025 & 0.0038 & 0.0048 & 0.0054 & 0.0060 \\
& $r_{0}$ & $5.3 \times 10^{-05}$ & $3.8 \times 10^{-05}$ & $2.5 \times 10^{-05}$ & $1.8 \times 10^{-05}$ & $1.3 \times 10^{-05}$ & $5.8 \times 10^{-05}$ \\
\hline
\end{tabular}

$C V_{q}$ variation $(\%)=100 \cdot\left(C V_{q}\right.$ constant $r_{0}-C V_{q}$ variable $r_{0} / C V_{q}$ constant $\left.r_{0}\right)$

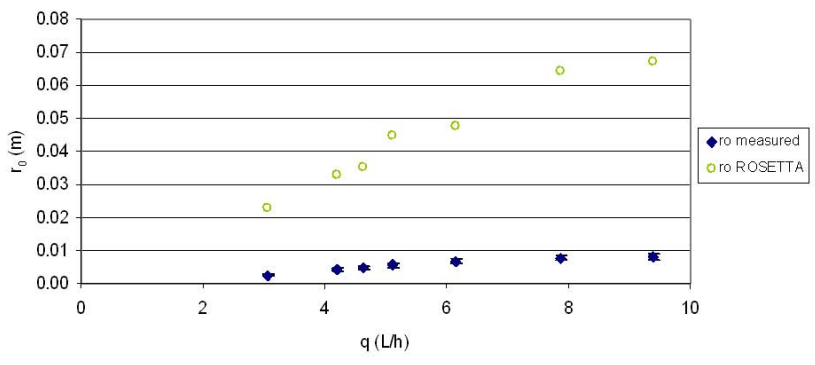

(a)

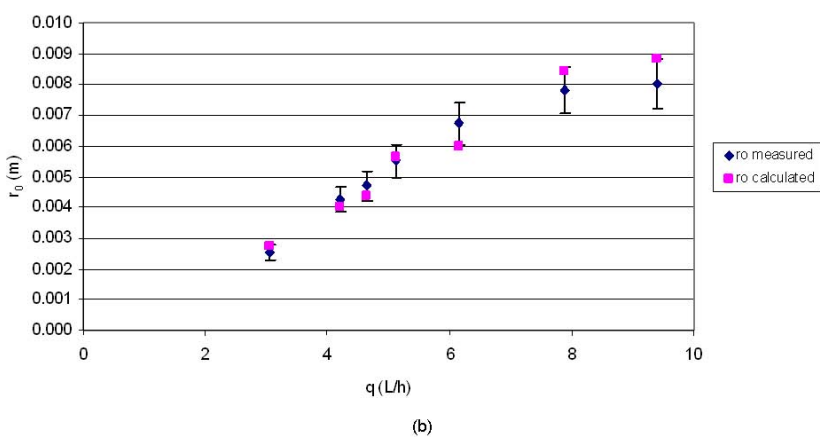

Fig. 5. Evolution of the equivalent spherical cavity radius ( $r_{0}$ equiv.) measured and estimated from ROSETTA values and those obtained with a different $\mathrm{K}_{s}$.

chosen such that the calculated $r_{0}$ would then be within a confidence interval of $10 \%$ of measured $r_{0}$ values. These results are presented in Fig. $5 b$.

The measured $r_{0}$ ( $r_{0}$ equiv) would probably be greater than that observed in field soil because, in these tests, the soil had no structure and the emitter outlet was shallow $(11 \mathrm{~cm})$. Thus, there was less weight from the overlying soil above the emitter outlet to counteract soil deformation.

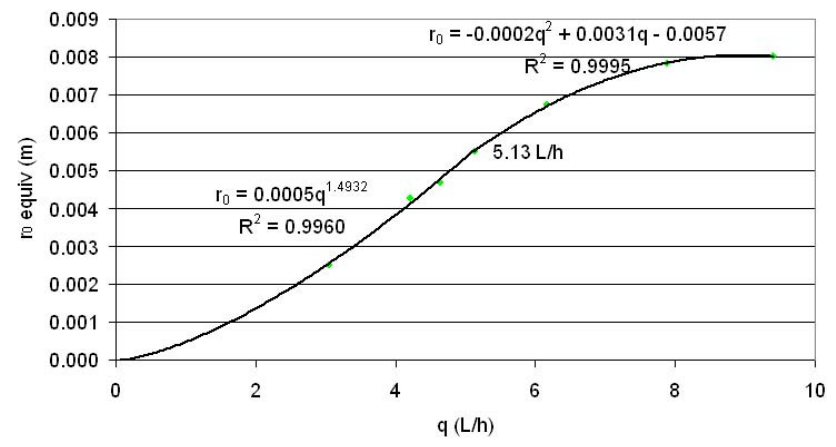

Fig. 6. Fitting equations used in the simulations.

\subsection{Simulation results}

The $q-r_{0}$ relationships were fitted to two different curves: an exponential for discharges of up to $5.13 \mathrm{~L} / \mathrm{h}$ and a polynomial for the remaining $q$ values (Fig. 6).

Table 5 depicts the irrigation-uniformity index, $C V_{q}$ (the coefficient of variance of the discharge); mean emitter discharge, $\bar{q}$; mean soil pressure at the emitter outlet, $\bar{h}_{s}$; mean cavity radius, $\bar{r}_{0}$; and its variability for the variable case $C V r_{0}$. (coefficient of variance of the cavity radius) Two different scenarios were considered: constant and variable $r_{0}$. The variation of $C V_{q}$ (percentage of the difference between the $C V_{q}$ in both cases divided by $C V_{q}$ in the constant situation) is also shown.

The greater the emitter discharge, $q$, the larger the observed cavity radius, $r_{0}$, as depicted in Table 5 .

The evolution of $h_{s}$ was not as expected, wherein it decreased for the smallest emitter discharges and then increased (Fig. 7). This performance matches the laboratory results (Fig. 4); however, these decreases and increases were not very large in the tested range, so the general trend was nearly constant in this range (Fig. 7). The simulated pressure in the soil exhibited the same trend (Fig. 7). Therein, the values did 


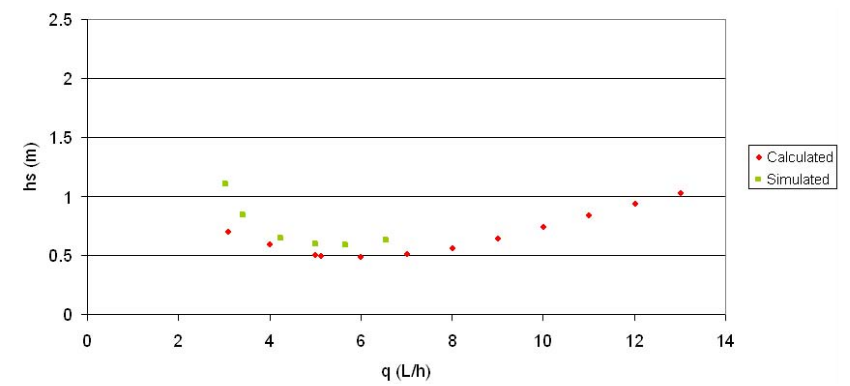

Fig. 7. Evolution of pressure in the soil around the emitter outlet as a function of emitter discharge: simulated and calculated values.

not exactly match, but in the case of the simulations, mean values in the unit were considered, so they did not have to be exactly the same.

But it was said before that $h_{s}$ is very sensitive to changes in $r_{0}$, and $r_{0}$ is strongly affected by $q$ and, at the same time, very similar $h_{s}$ were obtained. This sounds contradictory, but it occurred due to the direct relationship of $\mathrm{q}$ and $\mathrm{r}_{0}$ within the testing range and the constant inverse relationship of $r_{0}$ and $h_{\mathrm{s}}$. Thus, the higher the $q$, the higher $r_{0}$ is achieved and the resulting lower $h_{\mathrm{s}}$ occurred.

However, this increase of $r_{0}$ is not constant, as shown in Fig. $3 ; r_{0}$ has a linear increase with $q$ until it stabilizes. Then, $r_{0}$ becames steady, resulting in an increase in $h_{\mathrm{s}}$ with $q$ as the referee was expecting.

As expected, in uniform soils, the irrigation uniformity was high. Irrigation uniformity was higher for the smaller nominal emitter discharge (smaller $k$ ). This increase in $C V_{q}$ and subsequent decrease in uniformity can be observed in Fig. 8. The variation of $C V_{q}$ in both situations was bigger for the smaller discharge, although in all cases, it was small. For the high uniformity values, no difference was found in irrigation performance using either a variable or constant $r_{0}$. Future work will investigate simulations that consider soil spatial variability and different soil types.

\section{Conclusions}

The shape of the cavities observed around SDI emitters under test conditions in uniform soil samples in pots tended to be spherical at small emitter discharges. At higher emitter discharges, horizontal cracks were initially observed in the formed cavities, but were slowly filled with soil, ultimately resulting in a spherical cavity. Thus, Philip's (1992) assumption for water flow from buried emitters was confirmed. Measurements of the spherical cavity showed that its radius linearly increased with small emitter discharges and stabilized at higher discharges. The pressure decrease at the emitter outlet coincided with an increase in the size of the spherical cavity.

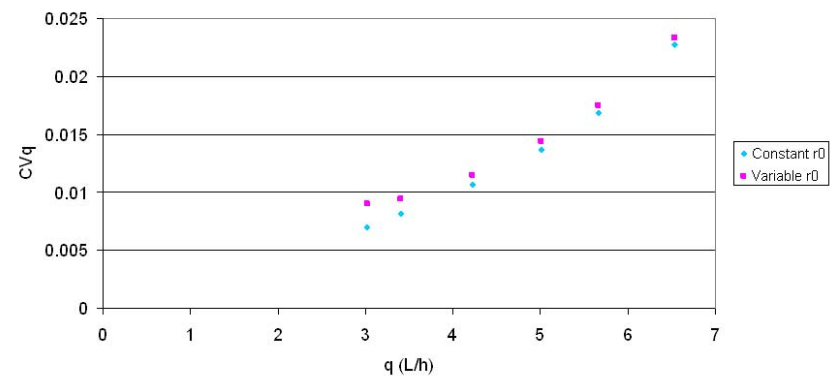

Fig. 8. Evolution of $C V_{q}$ as a function of discharge for both simulation cases.

\section{Supplementary material related to this article is available online at: http://www.biogeosciences.net/7/1983/2010/ bg-7-1983-2010-supplement.zip.}

Acknowledgements. The authors would like to thank the Spanish Interministry Science and Technology Board (CICYT) for its support of this work provided through project no. AGL200800153/AGR.

Edited by: A. M. Tarquis

\section{References}

Ben-gal A., Lazorovitch, N., and Shani, U.: Subsurface drip irrigation in gravel filled cavities, Vadose Zone J., 3, 1407-1413, 2004.

Day, P. R.: Particle fractionation and particle-size analysis, edited by: Black C. A., Methods of soil analysis, Part I: Agronomy, 9, 545-567, 1965.

Gardner, W. R.: Some steady state solutions of unsaturated moisture flow equations with application to evaporation from a water table, Soil Science 85, 228-232, 1958.

Gil, M., Rodríguez-Sinobas, L., Sánchez, R., Juana, L., and Losada, A.: Efecto del suelo en el caudal del gotero en riego subsuperficial, Determinación de caudales máximos, XXV Congreso Nacional de Riegos, Pamplona (España), 2007.

Gil, M., Rodríguez-Sinobas, L., Juana, L., Sánchez, R., and Losada, A.: "Emitter discharge variability of subsurface drip irrigation in uniform soils, Effect on water application uniformity", Irrig. Sci., 26, 451-458, 2008.

Karmeli, D. and Keller, J.: Trickle irrigation design, Rain Bird Sprinkler Manufact. Corp. Glendora, CA, 1975.

Lazarovitch, N., Simunek J., and Shani, U.: System dependent boundary conditions for water flow from a subsurface source, Soil. Sci. Soc. Am. J., 69, 46-50, 2005.

Lazarovitch, N., Shani, U., Thompson, T. L., and Warrick, A. W.: Soil hydraulic properties affecting discharge uniformity of gravity-fed subsurface drip irrigation, J. Irrig. Drain Eng., 132, 531-536, 2006.

Patel, N. and Rajput, T. B. S.: Dynamics and modeling of soil water under subsurface drip irrigated onion, Agr. Water Manage., 95(12), 1335-1349, 2008. 
Philip, J. R.: What happens near a quasi-linear point source? Water Resour. Res., 28, 47-52, 1992.

Rodriguez-Sinobas L., Gil, M., Sánchez R., and Juana, L.: Water distribution in subsurface drip irrigation Systems, I: Simulation, J. Irrig. Drain Eng., 135(6), 721-728, 2009a.

Rodriguez-Sinobas L., Gil, M., Sánchez, R., and Juana, L.: Water distribution in subsurface drip irrigation Systems, II: Field evaluation, J. Irrig. Drain Eng., 135(6), 729-738, 2009b.

Shani U. and Or, D.: In situ method for estimating subsurface unsaturated hydraulic conductivity, Water Resour. Res., 21, 1863$1870,1995$.
Shani U., Xue, S., Gordin-Katz, R., and Warrick, A. W.: Soillimiting from Subsurface Emitters, I: Pressure Measurements, J. Irrig. Drain Eng., 122, 291-295, 1996.

Van Genuchten, M. Th.: A closed-form equation for predicting the hydraulic conductivity of unsaturated soils, Soil. Sci. Soc. Am. J., 44, 892-898, 1980.

Warrick, A. W. and Shani, U.: Soil-limiting flow from subsurface emitters, II: Effect on uniformity, J. Irrig. Drain Eng., 122, 296300, 1996. 